\title{
Spatial orientation in man: effects of left, right, and bilateral posterior cerebral lesions ${ }^{1}$
}

\author{
GRAHAM RATCLIFF AND FREDA NEWCOMBE
}

From the Department of Neurology, The Churchill Hospital, Oxford

SUMMARY Men with chronic, penetrating missile wounds of the brain were examined with two 'spatial' tasks: a visually-guided stylus maze and a locomotor map-reading task. Men whose lesions involved the posterior part of the right cerebral hemisphere were significantly worse than those with left posterior lesions at stylus maze-learning. On the locomotor task, however, a highly significant deficit was found in the group of men with bilateral posterior cerebral lesions, while those with unilateral lesions of either hemisphere and those with bilateral frontal lesions were unimpaired. The contributions of the two cerebral hemispheres to the analysis of spatial information are discussed in the light of these results and it is suggested that, while the right hemisphere has a special role in the perception of space, it does not bear exclusive responsibility for the maintenance of spatial orientation.

Lange's conclusion that the right cerebral hemisphere is 'surprisingly' important for visual space perception (Lange, 1936) has had ample confirmation from more recent studies (Paterson and Zangwill, 1944; McFie, Piercy, and Zangwill, 1950; Ettlinger, Warrington, and Zangwill, 1957; Piercy, Hécaen, and Ajuriaguerra, 1960; Whitty and Newcombe, 1965; Milner, 1965; De Renzi and Faglioni, 1967; Warrington and James, 1967; Newcombe, 1969). But most of these studies have concentrated on the appreciation of spatial relationships in stimuli which the subject can explore without gross changes of position, while the separate but related field of topographical orientation has received comparatively little attention.

Furthermore, the locus of the lesion responsible for topographical disorientation is less certain: the disorder has been reported after damage to the posterior part of either or both hemispheres, the right being more frequently implicated (Kleist, 1934; Brain, 1941; Paterson and Zangwill, 1945; Pfeffer, Friedman, and Wortis, 1946; Cogan, 1960; De Renzi and Faglioni,

1 This work was supported by Medical Research Council Grants 967/90/C and 970/874/C and by a Medical Research Council Scholarship (G77/1333) to Graham Ratcliff.
1962; Hecaen, 1969), 'disorientation in space' has been described in cases of deep frontal $\mathbb{\Phi}$ damage (Marie and Béhague, 1919; Marie, Bouttier, and Van Bogaert, 1924), and it has been suggested that, in the absence of unilateral spatial agnosia, a bilateral lesion may be a necessary condition for topographical disorientation (McFie et al., 1950).

Experimental investigations using maze tasks have also shown that the locus of lesion producing maximal impairment depends on the nature of the 'spatial' task. Subjects with right hemisphere lesions, for example, take significantly longer than their counterparts with left hemisphere lesions to learn stylus maze paths (Corkin, 1965; Milner, 1965; Newcombe and Russell, 1969) and are impaired in the execution of 'perceptual' lattice mazes which do not involve the learning of a path (Benton, Elithorn, Fogel, and Kerr, 1963). On the other hand, Semmes, Weinstein, Ghent, and Teuber $(1955,1963)$ have reported a parietal deficit, irrespective of the hemisphere involved, on a locomotor maze task. In this task, unlike the stylus and lattice mazes, the subject changed his orientation with respect to the maze as he moved along the path; and the authors state that "men who complained that the injury had affected their sense of direction were 
among those who made the poorest scores on the test'.

The present study attempts to draw a distinction between experimentally defined deficits within the general area of spatial orientation, perhaps analogous to the clinical distinction between spatial agnosia and topographical disorientation, and to suggest different cerebral bases for the two types of spatial orientation. Two maze tasks were used and men with bilateral lesions as well as those with unilateral lesions of either hemisphere have been studied. The bilateral group was included because of the scarcity of information in the literature about the consequences of bilateral cerebral damage and because of its possible relevance to the problem of topographical disorientation (McFie et al., 1950).

\section{METHOD}

SUBJECTS The seventy-five experimental subjects were men with chronic missile wounds of the brain, drawn from the population of over one thousand ex-servicemen who had been patients at the Oxford Head Injuries Centre. The majority now work fulltime and attend the Churchill Hospital occasionally

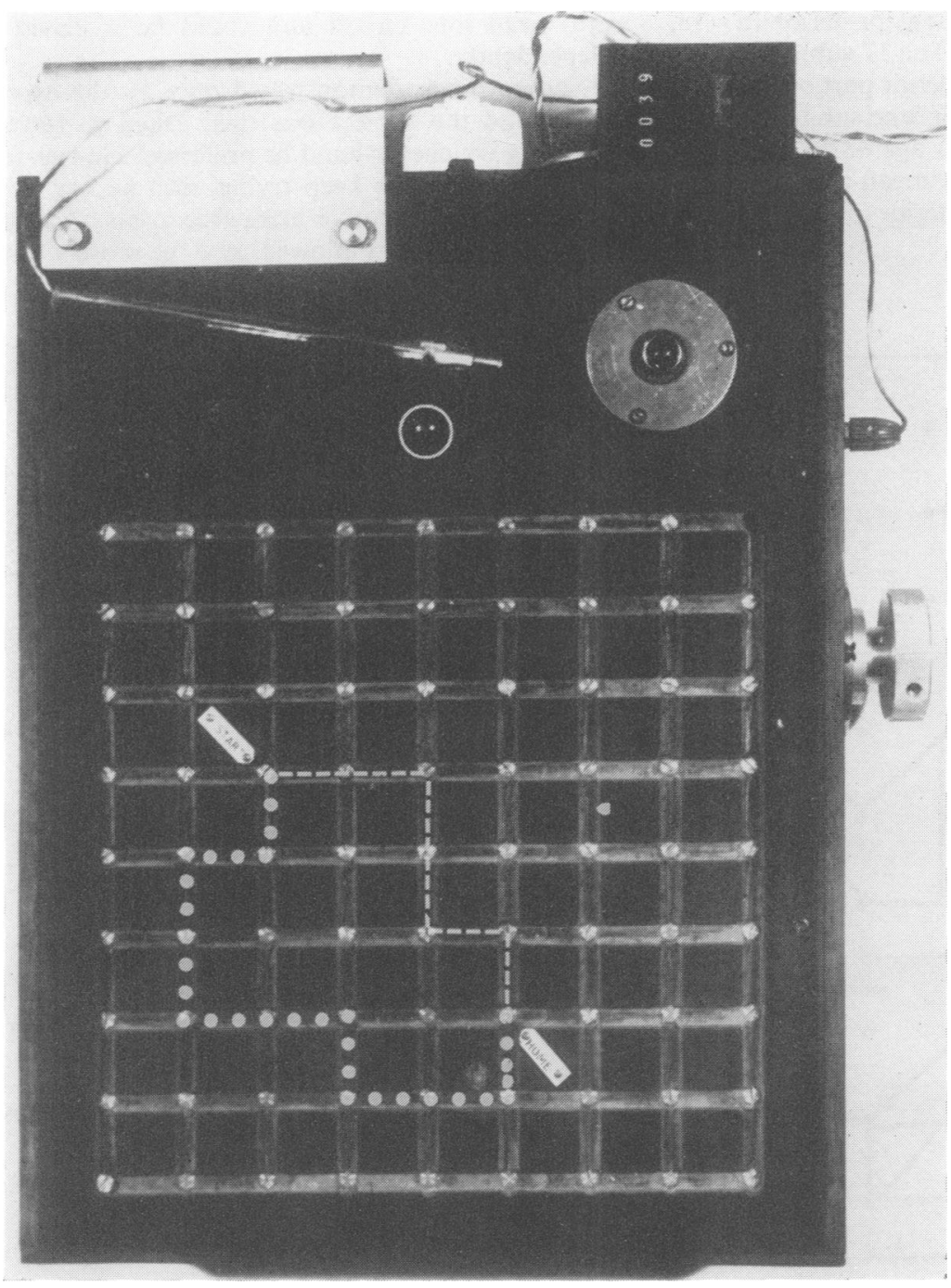

FIG. 1. Visually-guided maze learning task: apparatus. Practice path --_.... test path..... 
for follow-up examination. Left-handed men and those with evidence of cerebral disease were not considered.

Tracings of lateral and anteroposterior radiographs of the skull were made for each subject, noting the position of the skull defect and any indriven bone fragments or metal foreign bodies. Lesions were arbitrarily classified as 'posterior' if they involved tissue posterior to a line drawn through the post-central sulcus, and turned downwards through the temporal lobe parallel to the reference planes of Talairach and Szikla's stereotaxic atlas (Talairach and Szikla, 1967) - that is, the posterior parietal, posterior temporal, and occipital lobes. The posterior group was further subdivided into left posterior $(n=22$, mean age 49.5 years, standard deviation $5 \cdot 2$ years), right posterior $(n=18$, mean age 51.7 years, SD $5 \cdot 2)$, and bilateral posterior $(n=18$, mean age $47 \cdot 3$ years, SD 7.3). The 17 subjects whose lesions did not involve the posterior part of the brain were classified as 'non-posterior' and subdivided into left non-posterior $(n=5$, mean age 48.00 years, SD $6.7)$, right non-posterior $(n=5$, mean age 45.6 years, SD $2 \cdot 3)$, and bilateral non-posterior $(n=7$, mean age 46.9 years, SD 4.4 ).
The twenty control subjects were matched for age (mean age 49.7 years, SD 6.43), sex, and handedness. Eight were patients from the surgical wards of the hospital and 12 were volunteers who came specifically to assist in research. None gave any history of head injury or cerebral disease.

VISUALLY-GUIDED MAZE LEARNING The maze, which has been used in previous studies (Newcombe, 1969; Newcombe and Russell, 1969), is illustrated in Fig. 1. It consisted of an eight by eight arrangement of black $2 \mathrm{~cm}$ square blocks separated by a groove $6 \mathrm{~mm}$ deep and $6 \mathrm{~mm}$ wide. The subject ran a stylus along the groove. If he turned in the wrong direction a red light switched on with an audible click but no light or sound was produced by a correct move. Two paths, with six and 10 choice points respectively, were wired into circuit and could be switched in independently.

Each path was demonstrated once by the experimenter and the subject was then asked to trace it out, using whichever hand he preferred. He was told not to hurry and to keep trying until he had completed three consecutive error-free trials. A maximum of 25 trials was allowed, and the score was the

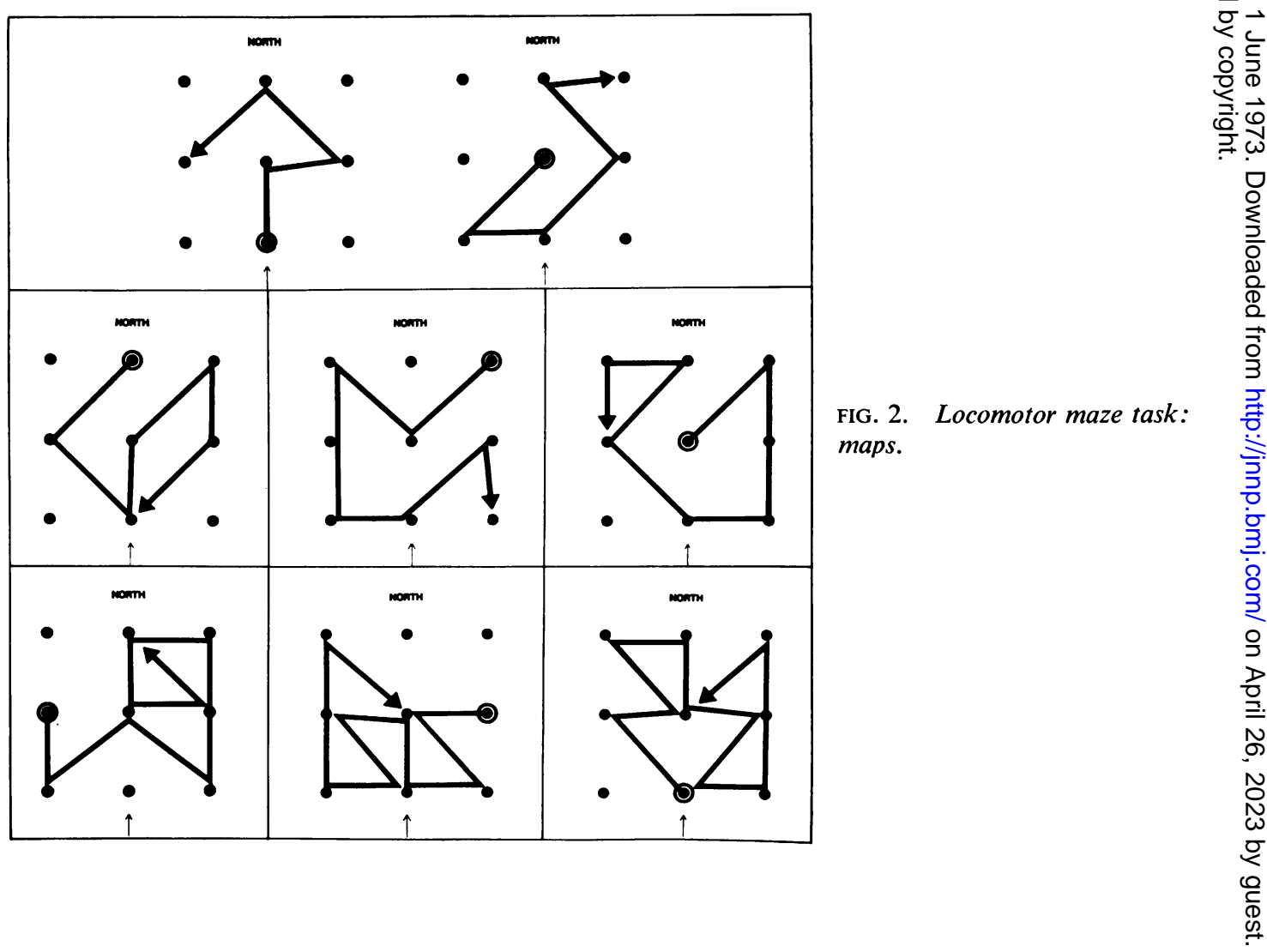


number of trials to criterion. The first path was regarded as practice and scores are reported only for path II. Seventy-five subjects attempted this task.

LOCOMOTOR MAZE This task was similar to the one used by Semmes, and her associates (Semmes et al., 1963; Weinstein, Semmes, Ghent, and Teuber, 1956), but differed in the elimination of tactual maps, the inclusion of an extra path of intermediate length, and the provision of two practice paths.

Eight maps (illustrated in Fig. 2) were drawn on $30 \mathrm{~mm}$ square sheets of white cardboard and covered with transparent film. Nine orange discs, $15 \mathrm{~cm}$ in diameter, were laid out approximately $150 \mathrm{~cm}$ apart in a three by three arrangement on the floor of a large room and the subject was required to walk from disc to disc along the path shown on the maps. A point was scored for each disc visited in its correct ordinal position. North was marked on each map and the wall of the room arbitrarily designated as North was distinguished by a clock and a set of parallel bars. The maps were always given to the subject on the South side of the room and he was asked to hold each map with the North side farthest from him throughout the trial. The map was thus in a constant orientation relative to the subject; but as he walked around the path his orientation relative to the room changed. Errors on the practice trials were corrected but no knowledge of results was given on test trials. Seventy-three subjects attempted this task.

\section{RESULTS}

The results are summarized in Tables 1 and 2 . Subjects with right posterior lesions took a greater number of trials than either of the other posterior groups to reach criterion on the stylus maze task. They were worse than controls at beyond the 0.002 level of confidence and were also significantly worse than the left posterior group. The bilateral posterior group was also

TABLE 1

MEAN SCORES OF CONTROL AND EXPERIMENTAL GROUPS

\begin{tabular}{lcccccc}
\hline \multicolumn{1}{c}{ Group } & \multicolumn{2}{c}{ Stylus maze } & & \multicolumn{2}{c}{ Locomotor maze } \\
\cline { 2 - 3 } \cline { 5 - 6 } & No. & Mean trials & & No. & Mean errors \\
\cline { 2 - 3 } & & & & & \\
\hline Control & 20 & 8.55 & & 20 & $6 \cdot 75$ \\
Left posterior & 22 & 10.00 & & 21 & $9 \cdot 19$ \\
Right posterior & 18 & 16.89 & & 18 & 8.61 \\
Bilat. posterior & 17 & 15.33 & & 18 & 22.78 \\
& & & & & \\
\hline
\end{tabular}

significantly worse than the control and left posterior groups on this task.

The locomotor maze task produced a strikingly different pattern of results. The bilateral posterior group was grossly impaired, being significantly worse than the control group, and each unilateral posterior group. No other group was significantly worse than controls. Indeed, 13 of the 18 subjects in the bilateral posterior group had locomotor maze scores which fell outside the control range while only five of the 39 subjects with unilateral posterior lesions had comparably low scores.

Impaired performance on this task could not be attributed to some variable associated with the existence of a bilateral lesion irrespective of

TABLE 2

SUMMARY OF STATISTICAL ANALYSIS (MANN-WHITNEY TEST)

\begin{tabular}{|c|c|c|c|c|}
\hline \multirow[t]{2}{*}{ Comparison } & \multicolumn{2}{|c|}{ Stylus maze } & \multicolumn{2}{|c|}{ Locomotor maze } \\
\hline & $U / z$ value & $\beta$ & $U / z$ value & $\beta$ \\
\hline Control $v$. left post. & $z=0.47$ & - & $z=0.78$ & - \\
\hline $\begin{array}{l}\text { Control } v \text {. right } \\
\text { post. }\end{array}$ & $\mathrm{U}=71$ & $<0.002$ & $\mathrm{U}=171 \cdot 5$ & 一 \\
\hline $\begin{array}{l}\text { Control } v \text {. bilat. } \\
\text { post. }\end{array}$ & $\mathrm{U}=41 \cdot 5$ & $<0.002$ & $U=25 \cdot 5$ & $<0.002$ \\
\hline $\begin{array}{l}\text { Left post. } v \text {. right } \\
\text { post. }\end{array}$ & $z=2 \cdot 75$ & $<0.01$ & $z=0 \cdot 39$ & - \\
\hline $\begin{array}{l}\text { Left post. } v \text {. bilat. } \\
\text { post. }\end{array}$ & $z=2 \cdot 41$ & $<0.05$ & $z=3.86$ & $<0.001$ \\
\hline $\begin{array}{l}\text { Right post. } v \\
\text { bilat. post. }\end{array}$ & $U=140$ & 一 & $\mathrm{U}=\mathbf{4 3}$ & $<0.002$ \\
\hline
\end{tabular}

TABLE 3

MEAN SCORES OF EXPERIMENTAL SUBJECTS GROUPED ACCORDING TO LOCUS OF LESION

\begin{tabular}{|c|c|c|c|c|}
\hline \multirow[t]{2}{*}{ Group } & \multicolumn{2}{|c|}{ Stylus maze } & \multicolumn{2}{|c|}{ Locomotor maze } \\
\hline & No. & Mean trials & No. & Mean errors \\
\hline \multicolumn{5}{|l|}{ Left } \\
\hline Pure posterior & 11 & $11 \cdot 64$ & 11 & $11 \cdot 00$ \\
\hline Mixed & 11 & $8 \cdot 36$ & 10 & $7 \cdot 20$ \\
\hline Non-posterior & 5 & $7 \cdot 20$ & 5 & 6.60 \\
\hline \multicolumn{5}{|l|}{ Right } \\
\hline Pure posterior & 8 & $16 \cdot 38$ & 8 & $10 \cdot 37$ \\
\hline Mixed & 10 & $17 \cdot 30$ & 10 & $7 \cdot 20$ \\
\hline Non-posterior & 5 & $12 \cdot 20$ & 4 & $11 \cdot 75$ \\
\hline \multicolumn{5}{|l|}{ Bilateral } \\
\hline Pure posterior & 9 & $16 \cdot 22$ & 10 & $25 \cdot 10$ \\
\hline Mixed & 8 & $14 \cdot 75$ & 8 & $19 \cdot 87$ \\
\hline Non-posterior & 7 & $9 \cdot 00$ & 7 & 6.43 \\
\hline
\end{tabular}


locus; seven subjects with bilateral lesions confined to the anterior portion of the brain were examined and found to be superior to those with bilateral posterior lesions at beyond the 0.002 level of confidence. Their mean score is shown in Table 3 and is slightly better than that of two small unilateral non-posterior groups.

Table 3 also further divides the posterior groups (those subjects with lesions involving the posterior part of the brain) into 'pure posterior' and 'mixed' subgroups (those with lesions confined to the posterior part of the brain and those with lesions involving both the posterior and anterior portions). The performance of the pure posterior subgroups tended to be slightly inferior to that of the mixed groups, although none of the differences reached statistical significance. Subjects with non-posterior lesions tended to perform better than those with lesions involving the posterior part of the brain but the scores of the unilateral non-posterior groups were not subjected to statistical analysis because of the small numbers in these groups and because the men in the right non-posterior group were, by chance, significantly younger than the rest of the men with right hemisphere lesions.

In no group and for neither task was poor performance associated with the presence or absence of clinically evident sensory-motor loss in the arm or the presence or absence of visual field defect (defined as failure to report the presence of the 3/330 white object of an Aimark projection perimeter over an area comprising a quarter or more of the visual field).

\section{DISCUSSION}

The impairment of the right posterior group on the stylus maze is consistent with previous reports of right hemisphere deficit on similar spatial tasks (Corkin, 1965; Milner, 1965; Newcombe, 1969; Newcombe and Russell, 1969). But the most interesting results in this study come from the locomotor maze task and they differ in two respects from those obtained by Semmes et al. $(1955$; 1963) with a similar task. We did not find a significant deficit in any unilateral group, and the striking difference in performance between subjects with unilateral and bilateral posterior lesions was not observed in their study (Teuber, 1964). The absence of im- pairment in our unilateral posterior groups is unlikely to be attributable to the different criteria used for the classification of lesions in the two studies, as the temporal parietal, and occipital groups defined by Semmes et al. each appear to have performed worse than the men in the unilateral posterior groups in the present study, most of whom had lesions involving the parietal lobes. The apparently better scores obtained in our study may reflect the inclusion of practice trials and the greater length of time that has elapsed since the injury in our cases.

The impairment of the bilateral posterior group on the locomotor maze task is the more remarkable as this group was slightly better than the right posterior group on the stylus maze task. The performance of individual subjects reflected this dissociation between the tasks: one man with a right posterior lesion, for example, failed to learn the visually-guided stylus maze path in 25 trials but made only one error on the locomotor maze, while another man, with a bilaterab posterior lesion, reached criterion on the stylus maze in five trials but made 40 errors (out of aD possible 57) on the locomotor maze.

The basis of this dissociation is interesting and reports of a similar dissociation in monkeys (Orbach, 1955; 1959) suggest that a difference if the nature of the tasks may be responsible. Or: bach attempted to demonstrate a deficit in the retention of a maze path after occipital lesions in rhesus monkeys (analogous to that demonstrated by Lashley (1943) in rats) but found that monkeys trained in the dark on a stylus maze retained the maze habit after lesions of the striate cortex. In an attempt to exclude the possibility that his failure to replicate Lashley's findings was determined by the type of maze used, Orbach trained a second group of monkeys on a locomotor maze of the same pattern. The monkeys were then peripherally blinded and brought back to criterion before being subjected to ablation of the striate cortex and retested. In contrast with the results for the stylus maze, bilateral lesions were found to have a consistently adverse effect on locomotor maze performance. Orbach (1959) comments: 'the locomotor maze required a shift in body position and, in the absence of vision, demands the development of a frame of reference for orientation. The stylus maze, on the other 
hand, permits the use of the body as a frame of reference'.

A similar analysis of the tasks used in this study is possible. The visually-guided stylus maze requires the subject to reproduce a path traced through a series of points in an array to which he maintains a constant orientation. It is suggested that defective appreciation of the relative positions of the choice points, or the relative directions of the elements of the path (and/or defective retention of this information), limited the performance of the right posterior group on this task. On the locomotor maze, on the other hand, the appreciation of the relative positions of the markers is initially comparatively simple, but it becomes difficult when the subject's orientation changes as he walks around. The failure to maintain orientation in a changing environment appeared to limit the performance of the bilateral posterior group on this test.

If this analysis is correct, the results may be relevant to the hypothesis that, in the absence of unilateral spatial agnosia, a bilateral lesion is an essential condition for topographical disorientation (McFie et al., 1950). Finding one's way, at least until a journey has become so practised as to be automatic, presupposes the ability to monitor changes in one's position relative to the environment; and the only subject in our sample who reported gross topographical memory loss and topographical disorientation became completely lost on the locomotor mazes. ${ }^{2}$ Recognizing his difficulty he studied the path before each trial and attempted to memorize it. $\mathrm{He}$ then walked around as much of the path as he could remember without referring to the map, and when he had done this was unable to go further.

However, there are undoubtedly other factors, apart from failure to maintain orientation in a changing environment and the neglect of one half of space (Brain, 1941), which contribute to abnormal difficulty in topographical orientation. The subject mentioned above, for example, reported that when he walked over frequently travelled routes in his home town the environment seemed unfamiliar, and the inability to recognize landmarks probably contributed to his disability. Impairment of route-finding in an

2 This patient was extensively studied by Spalding and Zangwill (1950). environment previously known to the patient has also been interpreted as an expression of an essentially mnestic disorder (Lange, 1936; De Renzi and Faglioni, 1962).

These other factors may have been operative in the cases in which topographical disorientation has followed a unilateral cerebral lesion; or damage to one hemisphere may be sufficient to cause a temporary disturbance of route finding, while impairment persists only in cases with bilateral lesions. All our subjects have had at least 20 years in which recovery from their injuries and compensation for their disabilities could have taken place. It is also possible that the essential feature of the bilateral posterior group in this study was not the existence of a bilateral lesion but involvement of the medial surface of one of the cerebral hemispheres.

Whichever is the case, it is clear from our results that the designation of either hemisphere as dominant for 'spatial' function would be premature. While the right hemisphere clearly has a special role in the perception of space (Paterson and Zangwill, 1944), and some aspects of conceptual spatial performance (McFie et al., 1950; Ratcliff, 1971), it does not bear exclusive responsibility for the maintenance of spatial orientation. Since the effects of a bilateral lesion are evidently not always equivalent to the sum of the effects of two unilateral lesions (Teuber, 1964; Benton, 1968; Ratcliff, 1971; Newcombe, Oldfield, Ratcliff, and Wingfield, 1971) the further elucidation of the roles of the two hemispheres and their interaction requires studies using a variety of spatial tasks and including subjects with bilateral as well as unilateral cerebral lesions.

We thank Professor W. Ritchie Russell and Professor Bryan Matthews for permission to study their patients and for their advice and encouragement. We are also grateful to Mr. M. H. Gough, Mr. J. C. Smith, and Mr. C. U. Webster for permission to test their patients as control subjects.

\section{REFERENCES}

Benton, A. L., Elithorn, A., Fogel, M. L., and Kerr, M. (1963). A perceptual maze test sensitive to brain damage, Journal of Neurology, Neurosurgery, and Psychiatry, 26, 540-544.

Benton, A. L. (1968). Differential behavioral effects in frontal lobe disease. Neuropsychologia, 6, 53-60. 
Brain, W. R. (1941). Visual disorientation with special reference to lesions of the right cerebral hemisphere. Brain, 64, 244-272.

Cogan, D. G. (1960). Hemianopia and associated symptoms due to parietotemporal lobe lesions. American Journal of Ophthalmology. 3rd series, 50, 1056-1066.

Corkin, S. (1965). Tactually-guided maze learning in man: effects of unilateral cortical excisions and bilateral hippocampal lesions. Neuropsychologia, 3, 339-351.

De Renzi, E., and Faglioni, P. (1962). Il disorientamento spaziale da lesione cerebrale. Sistema Nervoso, 14, 409-436.

De Renzi, E., and Faglioni, P. (1967). The relationship between visuo-spatial impairment and constructional apraxia. Cortex, 3, 327-342.

Ettlinger, G., Warrington, E. K., and Zangwill, O. L. (1957). A further study of visual-spatial agnosia. Brain, 80, 335361.

Hécaen, H. (1969). Aphasic, apraxic and agnosic syndromes in right and left hemisphere lesions. In Handbook of Clinical Neurology, Vol. 4, pp. 291-311. Edited by P. J. Vinken and G. W. Bruyn. North-Holland: Amsterdam.

Kleist, K. (1922/1934). Kriegsverletzungen des Gehirns in ihrer Bedeutung für die Hirnlokalisation und Hirnpathologie. In Handbuch der Arztlichen Erfahrungen im Weltkriege 1914/1918, Vol. 4, pp. 343-1390. Edited by O. von Schjerning. Barth: Leipzig.

Lange, J. (1936). Agnosien und Apraxien. In Handbuch der Neurologie, Vol. 6, pp. 807-960. Edited by O. Bumke and O. Foerster. Springer: Berlin.

Lashley, K. S. (1943). Studies of cerebral function in learning 12. Loss of the maze habit after occipital lesions in blind rats. Journal of Comparative Neurology, 79, 431-462.

McFie, J., Piercy, M. F., and Zangwill, O. L. (1950). Visualspatial agnosia associated with lesions of the right cerebral hemisphere. Brain, 73, 167-190.

Marie, P., and Béhague, P. (1919). Syndrome de désorientation dans l'espace consécutif aux plaies profondes du lobe frontal. Revue Neurologique, 26, 1-14.

Marie, P., Bouttier, H., and van Bogaert, L. (1924). Sur un cas de tumeur préfrontale droite. Troubles de l'orientation dans l'espace. Revue Neurologique, 31, T.2, 209-221.

Milner, B. (1965). Visually-guided maze learning in man: effects of bilateral hippocampal, bilateral frontal, and unilateral cerebral lesions. Neuropsychologia, 3, 317-338.

Newcombe, F. (1969). Missile Wounds of the Brain: a Study of Psychological Deficits. Oxford University Press: London.

Newcombe, F., and Russell, W. R. (1969). Dissociated visual perceptual and spatial deficits in focal lesions of the right hemisphere. Journal of Neurology, Neurosurgery, and Psychiatry, 32, 73-81.

Newcombe, F., Oldfield, R. C., Ratcliff, G. G., and Wingfield, A. (1971). Recognition and naming of object-drawings by men with focal brain wounds. Journal of Neurology, Neurosurgery, and Psychiatry, 34, 329-340.

Orbach, J. (1955). Nonvisual functioning of occipital cortex in the monkey. Proceedings of the National Academy of Sciences of the United States of America, 41, 264-267.

Orbach, J. (1959). Disturbances of the maze habit following occipital cortex removals in blind monkeys. Archives of Neurology and Psychiatry, 81, 49-54.

Paterson, A., and Zangwill, O. L. (1944). Disorders of visual space perception associated with lesions of the right cerebral hemisphere. Brain, 67, 331-358.

Paterson, A., and Zangwill, O. L. (1945). A case of topographical disorientation associated with a unilateral cerebral lesion. Brain, 68, 188-212.

Pfeffer, A. Z., Friedman, E. D., and Wortis, S. B. (1946). Cerebral lesion resulting in spatial disorientation. American Journal of Psychiatry, 103, 72-75.

Piercy, M. F., Hécaen, H., and Ajuriaguerra, J. de (1960). Constructional apraxia associated with unilateral cerebral lesions-left and right sided cases compared. Brain, 83, 225-242.

Ratcliff, G. G. (1971). Aspects of Disordered Space Perception. Unpublished Doctoral thesis. University of Oxford.

Semmes, J., Weinstein, S., Ghent, L., and Teuber, H.-L. (1955). Spatial orientation in man after cerebral injury: 1. Analyses by locus of lesion. Journal of Psychology, 39, 227 244.

Semmes, J., Weinstein, S., Ghent, L., and Teuber, H.-L. (1963). Correlates of impaired orientation in personal and extrapersonal space. Brain, 86, 747-772.

Spalding, J. M. K., and Zangwill, O. L. (1950). Disturbance of number-form in a case of brain injury. Journal of Neurology, Neurosurgery, and Psychiatry, 13, 24-29.

Talairach, J., and Szikla, G. (1967). Atlas d'Anatomie Stéréotaxique du Télencéphale. Masson: Paris.

Teuber, H.-L. (1964). The riddle of frontal lobe function in man. In The Frontal Granular Cortex and Behavior. pp. 410-444. Edited by J. M. Warren and K. Akert, McGraw-Hill: New York.

Warrington, E. K., and James, M. (1967). Tachistoscopic: number estimation in patients with unilateral cerebral lesions. Journal of Neurology, Neurosurgery, and Psychiatry, 30, 468-474.

Weinstein, S., Semmes, J., Ghent, L., and Teuber, H.-L. (1956). Spatial orientation in man after cerebral injury: 2. Analysis according to concomitant defects. Journal of Psychology, 42, 249-263.

Whitty, C. W. M., and Newcombe, F. (1965). Disabilities associated with lesions in the posterior parietal region of the non-dominant hemisphere. Neuropsychologia, 3, 175185. 